\title{
Role of ormeloxifene in AUB/HMB
}

\author{
Uma Pandey \\ Associate Professor, Dept. of Obstetrics and Gynaecology, Institute of Medical Sciences, Banaras Hindu University, Varanasi, \\ Uttar Pradesh, India
}

*Corresponding Author:

Email: uma.pandey2006@yahoo.com

Received: $28^{\text {th }}$ September, 2017

Accepted: $20^{\text {th }}$ January, 2018

\begin{abstract}
Introduction: Heavy menstrual blood loss is defined as $>80 \mathrm{ml}$ of blood loss during menstruation. Abnormal uterine bleeding is abnormal menstruation as regards volume, regularity, frequency and duration of bleeding.

Materials and Methods: A total of 100 patients of age group 25-45 years were included in this study. Patients were thoroughly investigated before inclusion. Exclusion criteria were any women with fibroid, adenomyosis, endometrial hyperplasia, breast cancer and coagulopathy. Patients were thoroughly investigated before therapy. Ormeloxifene was administered orally $60 \mathrm{mg}$ twice a week for 3 months followed by $60 \mathrm{mg}$ once a week for a month.

Results: Amenorrhoea was 33\% at 3 months follow up which is increased further to $42 \%$ at 4 months follow up. Similarly $44 \%$ women had scanty flow at the end of 4 months treatment. Comparison of clinical characteristics shows reduction in duration of menstrual blood loss and rise in haemoglobin (from 7.2 to $9 \mathrm{gm} / \mathrm{dl}$, which is along with oral iron supplementation). Passage of blood also reduced considerably, although 7 (7.4\%) women did not show good response.

Conclusion: The study concluded that ormeloxifene is a good option as it is cheap, has twice weekly schedule, few side effects and efficacious in reducing the menstrual blood loss.
\end{abstract}

Keywords: Heavy menstrual blood loss, Abnormal uterine bleeding, Fibroid, Adenomyosis, Ormeloxifene.

\section{Introduction}

Heavy menstrual blood loss is defined as $>80 \mathrm{ml}$ of blood loss during menstruation. Abnormal uterine bleeding is abnormal menstruation as regards volume, regularity, frequency and duration of bleeding. ${ }^{1}$

Menstruation starts at approximately the age of 12 and 14 years and persists throughout the reproductive period of life with an average cycle of 28 days and duration of flow between 4-6 days. A normal menstrual blood loss is $50-80 \mathrm{ml}$ and does not exceed $100 \mathrm{ml} .^{2}$

Menstrual disorders are a cause of great inconvenience, discomfort and disruption to a healthy lifestyle and affect many women in both the developed and developing world. Abnormal uterine bleeding (AUB) is one of the commonest problems that are encountered by the Gynecologists. A full workup is essential because of the consequences of bleeding and the implications of the treatment.

Most of the gynaecology consultations are among the reproductive age group women is due to heavy menstrual blood loss. A study by Nicholson et al in the USA found that $19 \%$ of women had menstrual disorder. $^{3}$

Clinical consultation in a patient of abnormal uterine bleeding (AUB) should involve thorough history and examination along with relevant investigations. FIGO' menstrual disorders working group has proposed new classification system of etiology of AUB (Table 1). ${ }^{1}$
Table 1: FIGO' menstrual disorders working group classification AUB ${ }^{1}$

\begin{tabular}{|l|c|}
\hline \multicolumn{1}{|c|}{ PALM } & COEIN \\
\hline Polyp & Coagulopathy \\
\hline Adenomyosis & Ovulatory dysfunction \\
\hline Leiomyoma & Endometrial \\
\hline $\begin{array}{l}\text { Malignancy and } \\
\text { Hyperplasia }\end{array}$ & Iatrogenic \\
\hline & Not yet classified \\
\hline
\end{tabular}

Treatment of AUB depends upon etiology, age of the women, desire of fertility and options available. Favored medical options include combined oral contraceptive pills, progestins, LNG IUS (Levonorgestrel Intrauterine System), tranexamic acid and GnRh analogues (Gonadotrophic Releasing Hormone analogues). These medicines have their side effects and come with a cost as well.

Ormeloxifine is a newer non-steroidal medicine, which is recommended for AUB, although there is not enough robust data regarding its efficacy and side effect. It is a selective estrogen receptor modulator, which has estrogen antagonistic action on the uterus and breast tissue but mild agonistic action on bone mineral density. ${ }^{4}$

Ormelxifene is efficacious; it reduces $70 \%$ of blood loss with few side effects. It requires oral administration and dosage schedule is user friendly. Ormeloxifene is not an expensive medicine. ${ }^{5}$

Ormeloxifene, one of the selective estrogen receptor modulator has high affinity to estrogen receptors (ER) and mimics the effect of estrogen in 
some tissues but act as estrogen antagonists in others. Ormeloxifene has its effects by high affinity binding with Estrogen Receptors, antagonizing the effect of estrogen on uterine and breast tissue and stimulating its effect on vagina, bone, cardiovascular system and central nervous system. ${ }^{6}$

Ormeloxifene has no significant effect on pituitary gonadotropin level. The drug causes amenorrhoea as its common side effect. The drug can normalize the abnormality locally at the level of uterine endometrium without effecting hypothalamo-pituitary-ovarian axis. Ormeloxifene has got an excellent safety profile and been found to have very few side effects limited to gastro intestinal symptoms, weight gain and amenorrhoea. $^{7-8}$

\section{Materials and Methods}

A total of 100 patients of age group 25-45 years were included in this study. Patients were thoroughly investigated before inclusion. Exclusion criteria were any women with fibroid, adenomyosis, endometrial hyperplasia, breast cancer and coagulopathy. Patients were thoroughly investigated before therapy.

Ormeloxifene was administered orally $60 \mathrm{mg}$ twice a week for 3 months followed by $60 \mathrm{mg}$ once a week for a month.
Patients were asked regarding number of usage of pads, menstrual flow, duration of menstrual loss, passage of blood clot. Their haemoglobin was measured pre and post treatment.

\section{Results}

Total of 100 patients were prescribed ormeloxifene and followed up. Average age of the patients was 38 years and parity was 3 .

Patients were asked regarding number of usage of pads, menstrual flow, duration of menstrual loss, passage of blood clot. Their haemoglobin was measured pre and post treatment.

Amenorrhoea was $33 \%$ at 3 months follow up which is increased further to $42 \%$ at 4 months follow up. Similarly $44 \%$ women had scanty flow at the end of 4 months treatment. (Table 2)

Comparison of clinical characteristics (as shown in Table 3) shows reduction in duration of menstrual blood loss and rise in haemoglobin (from 7.2 to 9 $\mathrm{gm} / \mathrm{dl}$, which is along with Oral Iron supplementation). Passage of blood also reduced considerably, although 7 (7.4\%) women did not show good response.

Side effects were minimal and were in the form of vague lower abdominal pain (in $7 \%$ women) only.

Table 2: Effect of ormeloxifene

\begin{tabular}{|l|c|c|c|}
\hline \multicolumn{1}{|c|}{ Menstrual pattern } & Pre-treatment & 3 month & 4 month \\
\hline Amenorrhoea & 0 & $32(33.33 \%)$ & $40(42.55 \%)$ \\
\hline Scanty flow & 0 & $23(23.95 \%)$ & $42(44.68 \%)$ \\
\hline Moderate flow & $12(12 \%)$ & $21(21.87 \%)$ & $12(12.76 \%)$ \\
\hline Heavy flow & $70(70 \%)$ & $19(19.79 \%)$ & 0 \\
\hline Very heavy flow & $18(18 \%)$ & $1(1.04 \%)$ & 0 \\
\hline Total & $100(100 \%)$ & $96(100 \%)$ & $94(100 \%)$ \\
\hline
\end{tabular}

Table 3: Comparison pre and post treatment

\begin{tabular}{|l|c|c|}
\hline \multicolumn{1}{|c|}{ Clinical characteristics } & Pre-treatment & Post-treatment (4months FU) \\
\hline Duration of menstrual loss & 8 days & 4 days \\
\hline Average $\mathrm{Hb}$ & $7.2 \mathrm{gm} / \mathrm{dl}$ & $9 \mathrm{gm} / \mathrm{dl}$ \\
\hline Passage of blood clots & $\mathrm{N}=30$ & $\mathrm{~N}=2$ \\
\hline No response & $\mathrm{N}=\mathrm{N} / \mathrm{A}$ & $\mathrm{N}=7(7.44 \%)$ \\
\hline Total & $\mathrm{N}=100$ & $\mathrm{~N}=94$ \\
\hline
\end{tabular}

\section{Discussion}

Abnormal uterine bleeding was found to be third most common cause in an audit of hysterectomies in teaching hospital of India. ${ }^{9}$

Menorrhagia accounts for most of the referrals to gynaecological outpatients department. Age group of menorrhagia/HMB/AUB is commonly between 30-45 but can present even in younger age groups.

The traditional surgical treatment for HMB/AUB is hysterectomy but it may not be suitable for everybody. Some might have medical fitness problems; others can have financial or social difficulties. Hysterectomies or endometrial ablations can only be done once the family is complete. Hysterectomies or endometrial ablations also have postoperative morbidity or mortality.

For women with $\mathrm{HMB} / \mathrm{AUB}$, who wish to retain fertility, there are various medicines which are available. Antifibrinolytics, non-steroidal antiinflammatory drugs, progesterones, combined estrogen and progesterone, danazol, GnRH analogues and levonorgestrel releasing intra uterine devices have all been used with varying results. ${ }^{6-8}$

Levonorgestrel devices are very effective but are expensive. Danazol, GnRH analogues are also effective but their side effects deter them from using for long term. 
Ormeloxifene has shown promise in the management of AUB or heavy menstrual blood loss in this small study conducted in a teaching hospital. Hysterectomy is the definitive treatment in cases of AUB but it has its own complication of a major operative procedure. ${ }^{10}$

In our teaching hospital a major proportion of women come from underprivileged, anaemic, poor and illiterate. Surgery is not the first choice in them, neither the expensive medicines for AUB like GnRH analogues. Oral contraceptive pills have side effect like nausea, vomiting, breast tenderness and LNG IUS is expensive.

Considering the above ormeloxifene is a good option as it is cheap, has twice weekly schedule, few side effects and efficacious in reducing the menstrual blood loss. ${ }^{4}$

The finding of this study is in similar to study by Kriplani and Komaram et al in terms of haemoglobin rise and menstrual symptoms. ${ }^{4,6}$

This study concludes that ormeloxifene is a good and effective drug and should be preferably given as first choice in the management of AUB, more so in perimenopausal women in whom scanty periods and amenorrhea is acceptable.

Limitations of this study are patient sample, nonrandomization and follow up duration. A large randomized controlled trial in our set up (tertiary referral hospital) would further validate the findings and contribute to scientific knowledge.

\section{Conclusions}

HMB/AUB is a very common disorder at all ages from menarche to menopause. Our study concluded that ormeloxifene is suitable for the treatment of HMB/AUB in wide age groups with effective therapeutic safety and with least side effects. This study also showed that the compliance of the patients is good. Thus, ormeloxifene can be considered as an effective and safe therapeutic option for the medical management of $\mathrm{HMB} / \mathrm{AUB}$.

Ormeloxifene, a SERM "Selective estrogen receptor modulators" because they are designed to act in specific way at each of the receptor site, is a wonderful drug.

This study shows a way by which surgical procedures for menorrhagia can be reduced along with its mortality and morbidities.

\section{List of Abbreviations}

AUB/HMB (Abnormal Uterine Bleeding/Heavy Menstrual Bleeding)

LNG IUS (Levonorgestrel Intrauterine System)

GnRh analogues (Gonadotrophic Releasing Hormone analogues)

Acknowledgment: I would like to thank my patients.

\section{Conflict of Interest: Nil}

\section{References}

1. Munro MG, Critchley HO, Border MS, et al. FIGO classification system (PALM-COEIN) for causes of abnormal uterine bleeding in non-gravid women of reproductive age. FIGO working group on Menstrual disorders. Int J Gynaecol Obstet. 2011;113-3-13.

2. James M and Shwayder MD. Pathophysiology of abnormal uterine bleeding, contemporary management of abnormal uterine bleeding. Obstetrics and Gynaecology of North America. 2000;27(2):219-34.

3. Nicholson WK, Ellison SA, Grason H, et al. Patterns of ambulatory care use for gynaecologic conditions: a national study. Am J Obstet Gynecol. 2001;184:523-30.

4. Nigam M, Ranjan V, Srivastava S, et al. Centchroman induces G0/G1 arrest and caspase-dependent apoptosis involving mitochondrial membrane depolarization in MCF-7 and MDA MB-231 human breast cancer cells. Life Sci. 2008;82(11-12):577-90.

5. Kriplani A, Kulshrestha V, Agarwal N. Efficacy and safety of ormeloxifene in management of menorrhagia: a pilot study. J Obstet Gyecol Res. 2009;35:746-52.

6. Shelly W, Draper MW, Krishnan V, Wong M, Jaffe RB. The selective estrogen receptor modulators: an update on the recent clinical findings. Obstet Gynecol Surv. 2008;63(3):163-81.

7. Biswas SC, Saha SK, Bag TS et al. Ormeloxifene a selective estrogen receptor modulator, for treatment of dysfunctional menorrhagia. J Obstet Gynecol Ind. 2004;54(1):56-59.

8. Singh MM, Kamboj VP. Effect of prolonged centchroman treatment on pituitary gonadotrophic activity in rhesus monkeys. Indian J Exp Biol. 1991;29(12):1145-6.

9. Pandey D, Sehgal K, Saxena A, et al. An audit of indications, complications and justification of hysterectomies at a teaching hospital in India. Int $J$ Reprod Med. 2014, Article ID 279273, 6b.

10. Komaram R, Palla J, Chintada GS. A study of Ormeloxifene in the Pharmacological Management of DUB. J Clin Diagn Res. 2013;7(11):2534-6.

How to cite this article: Pandey U. Role of ormeloxifene in AUB/HMB. Ind $\mathrm{J}$ Obstet Gynecol Res. 2018;5(3):392-394. 